Tropical Journal of Pharmaceutical Research July 2018; 17 (7): 1439-1444

ISSN: $1596-5996$ (print); 1596-9827 (electronic)

(C) Pharmacotherapy Group, Faculty of Pharmacy, University of Benin, Benin City, 300001 Nigeria.

\title{
Dispensing patterns of antimigraine agents with a focus on seasonal variations in prescribing
}

\author{
Ilse Truter*, Bernadette Louwrens, Theunis J van W Kotze \\ Drug Utilization Research Unit (DURU), Nelson Mandela University, Port Elizabeth, South Africa \\ ${ }^{*}$ For correspondence: Email: ilse.truter@mandela.ac.za; Tel: +27-41-5042131; Fax: +27-41-5041091
}

Sent for review: 24 August 2017

Revised accepted: 16 June 2018

\begin{abstract}
Purpose: To determine the dispensing patterns of antimigraine agents in a private healthcare setting, focusing on seasonal variations in prescribing.

Methods: A retrospective, cross-sectional drug utilization study was conducted using a South African medical insurance scheme administrator database for 2016. The database contained 3567170 records for medicines, medical devices and procedures. All products in MIMS category 1.9 (antimigraine agents) were analysed.

Results: $A$ total of 914 antimigraine products were dispensed to 505 patients (69.70 \% females) at a cost of US $\$ 10,988.63$. The average age of patients was $41.57(S D=13.77)$ years. Of the eight active ingredients, clonidine was the most often dispensed (34.68 \%), followed by rizatriptan (28.01\%) and ergotamine (26.04\%). Prescribing peaks were observed in February to April 2016, and again in October. These months coincide with the change in seasons to winter and to summer, respectively, in South Africa.

Conclusion: The sample size was too small to make definite conclusions, but it seems that prescribing of antimigraine agents reaches a peak during seasonal change specifically autumn and spring, confirming that weather is a possible trigger factor in migraine.
\end{abstract}

Keywords: Migraine, Antimigraine agents, Trigger factors, Environmental, Weather, Seasonal, Prescribing patterns, Rizatriptan

\footnotetext{
This is an Open Access article that uses a funding model which does not charge readers or their institutions for access and distributed under the terms of the Creative Commons Attribution License (http://creativecommons.org/licenses/by/4.0) and the Budapest Open Access Initiative (http://www.budapestopenaccessinitiative.org/read), which permit unrestricted use, distribution, and reproduction in any medium, provided the original work is properly credited.

Tropical Journal of Pharmaceutical Research is indexed by Science Citation Index (SciSearch), Scopus, International Pharmaceutical Abstract, Chemical Abstracts, Embase, Index Copernicus, EBSCO, African Index Medicus, JournalSeek, Journal Citation Reports/Science Edition, Directory of Open Access Journals (DOAJ), African Journal Online, Bioline International, Open-J-Gate and Pharmacy Abstracts
}

\section{INTRODUCTION}

The International Classification of Headache Disorders describes migraine as "a common disabling primary headache disorder" [1]. Migraine was ranked as the third most prevalent disorder and seventh-highest specific cause of disability worldwide in the Global Burden of Disease Survey 2010 [2]. The term "headache (or migraine) trigger" is used to describe a stimulus that alone or in combination, contributes to the onset of a headache (or migraine) attack on predisposed individuals [3]. Knowledge about migraine trigger factors is important in the management of migraine because the avoidance of these factors may result in better control of the disorder [4]. Various trigger factors have been identified, for example [3,5] dietary factors, hormonal factors, sleep habits, environmental 
factors, stress levels and participation in certain activities (such as exercise).

The impact of environmental factors on the clinical manifestation of migraine has been, a matter of "extensive debate over the past decades" [6]. Weather changes are empirically known to trigger migraine attacks [5,7]. Although not all studies could find a link between weather factors and migraine [8,9], some studies have reported a significant correlation $[5,10,11]$. In a study conducted in Greece [3], the literature review highlighted the following most frequently mentioned trigger factors: stress, skipping meals, sleep deprivation and weather changes [12-14]. Examples of weather trigger factors were temperature changes, high humidity, high winds, sun glare and bright light, barometric pressure changes, stormy weather and extremely dry conditions $[15,16]$.

According to estimates, $7 \%$ to $61 \%$ of migraineurs report weather as a trigger factor [17]. Studies of weather sensitivity reported some seasonal variation in migraine attacks [18]. In the study by Robbins [19] increased migraine attacks were reported by $14 \%$ of migraineurs in spring, followed by fall (13\%), summer (11\%) and winter $(7 \%)$. A case study comprising of migraineurs with aura over a six year period, indicated that auras occurred predominantly in spring and autumn [20]. Furthermore, two-thirds of migraineurs in the arctic reported seasonal variations in migraine [21].

Various studies have definitively identified weather as a migraine trigger factor. The primary aim was to determine the dispensing patterns of antimigraine agents in a private healthcare setting in South Africa, with the focus on seasonal variations in the prescribing of these agents.

\section{METHODS}

\section{Study design and setting}

A retrospective, cross-sectional drug utilization study was conducted using a private sector medical aid claims database. The database covered the period 1 January 2016 to 31 December 2016 and consisted of 3567170 records for medicine, medical devices and procedures from general medical practices, pharmacies, private hospitals, day clinics and sub-acute facilities, to give a comprehensive overview of antimigraine prescribing patterns. Patients from all areas (provinces) in South Africa were included in the study.

\section{Data analysis}

All products in the Monthly Index of Medical Specialities (MIMS) category 1.9 (Antimigraine agents) [22] were extracted and analysed. Each medication record consisted of the following fields: gender and age of the patient, a unique number to identify each patient, the date of the prescription, detailed information on the dispensed drug (name, package size, formulation, strength and quantity) and sales value. Limitations of the study included that no diagnoses or clinical information were available, and that the type and/or intensity of migraine was not known.

The Anatomic Therapeutic Chemical (ATC) classification system [23], MIMS [22] and the South African Medicines Formulary [24] were used to identify the medicines that were prescribed. The database did not include detailed diagnoses codes (ICD-10 codes) [25]. Microsoft Access $^{\circledR}$ and Excel $^{\circledR}$ were used to analyse the data. Descriptive statistics were calculated. The costs indicated in the study were the amount paid by the respective medical insurance schemes who are administered by the medical insurance scheme administrator. One Euro $(€ 1.00)$ was equal to R16.36 (South African Rand), one US Dollar (\$1.00) was equal to R14.77 and one British Pound (£1.00) was equal to R19.58 at the time of the study (30 June 2016).

\section{Ethical approval}

Ethical approval to conduct the study was obtained from the Research Ethics Committee (Human) of the Nelson Mandela University (ethics clearance no. H08-HEA-PHA-005). The study was conducted in accordance with the principles set out in the Belmont Report [26]. No patient or prescriber was identified.

\section{RESULTS}

\section{Demographic information of patients}

A total of 505 patients (69.70\% females) received one or more antimigraine agents. The average age of patients was $41.57(\mathrm{SD}=13.77)$ years. The age interval of 35 to 64 years contained $62.38 \%$ of the patients. The average age of female patients was $42.51(S D=13.30)$ years and of male patients $39.41(S D=14.63)$ years. The age and gender distribution of patients are given in Figure 1. There was a significant difference in the distribution of the number of females and males in the different age groups $\left(\mathrm{chi}^{2}=17.7\right.$; d.f. $\left.=6, \mathrm{p}<0.05\right)$. There 
were proportionally more male patients in the younger age groups up to the age of 40 years, where after there were generally more female patients in the older age groups.

The 505 patients received 914 antimigraine products during the year (average of 1.81 (SD = 1.85) products at a cost of R167 302.00. Female patients received an average of $1.98(\mathrm{SD}=1.94)$ antimigraine products and male patients 1.42 $(S D=1.58)$ antimigraine products over the year.

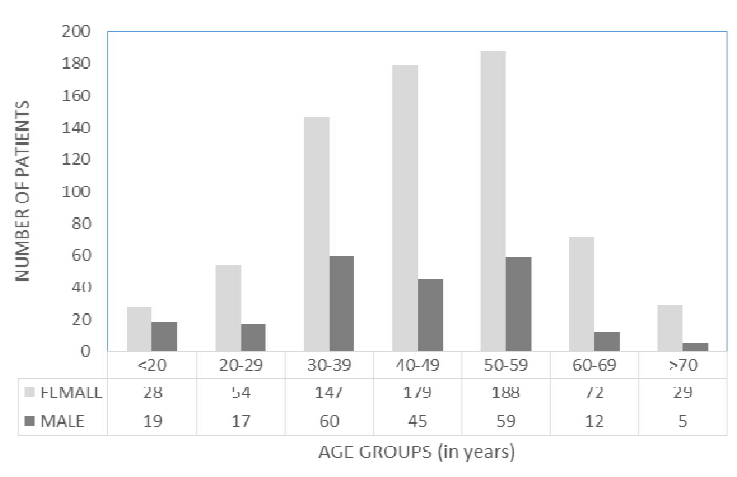

Figure 1: Age and gender distribution of patients ( $\mathrm{n}=$ 914). ${ }^{* *} \mathrm{Chi}^{2}=17.7$; d.f. $=6, p<0.05$

\section{Active ingredients prescribed}

Most of the 914 antimigraine products (78.01\%) were dispensed by pharmacies, followed by private hospitals (18.82 \%) and general medical practices (2.95\%). Eight active ingredients were dispensed (see Figure 2). Clonidine was the most often dispensed (34.68 \%), followed by rizatriptan (28.01\%) and ergotamine (26.04\%). Proportionally, more clonidine prescriptions were dispensed to females than to males (39.31\% versus $19.82 \%$ ).

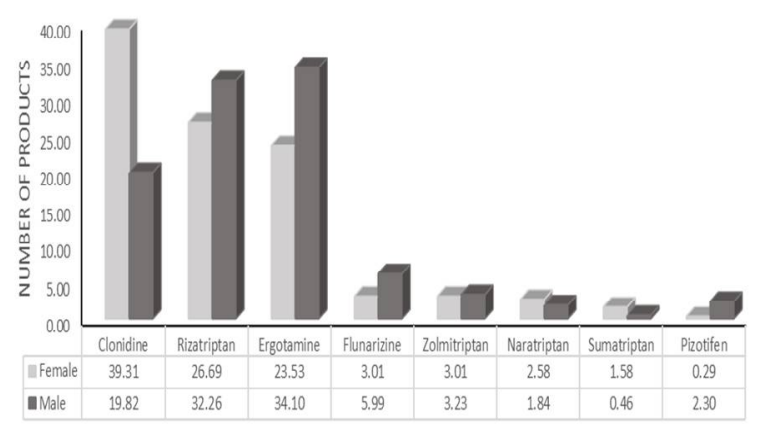

Figure 2: Active ingredients prescribed according to gender in decreasing order of frequency $(n=914)$

\section{Seasonal variations in the prescribing of antimigraine agents}

Figure 3 indicates the seasonal variations in the prescribing patterns of the different classes of antimigraine agents. It can be observed from
Figure 3 that there was a general decrease in prescription frequency towards the end of the year. There was, however, a clear peak in the prescribing frequency of rizatriptan just before the summer holiday period (during October).

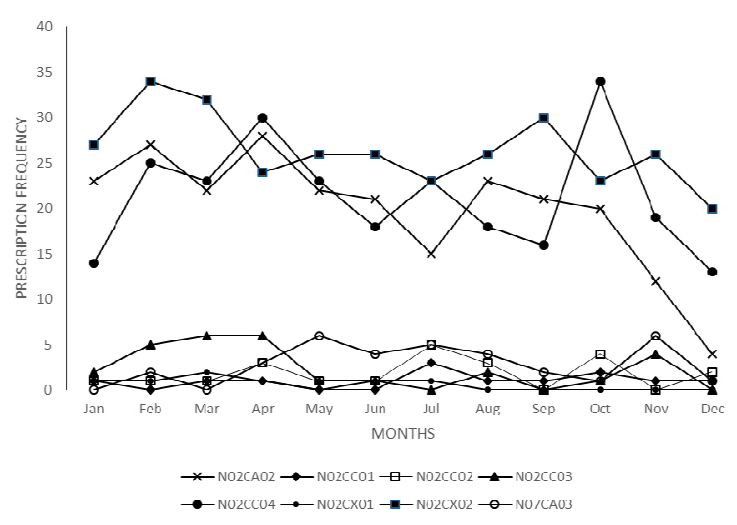

Figure 3: Prescription frequencies of different classes of antimigraine agents $(n=914)$

Figure 4 indicates the combined frequencies with the average indicated. Three of the eight active ingredients were selected with a-priori knowledge (from collected data), and overall indicated a chisquare of 27.33 (d.f. $=11 ; p<0.01$ ).

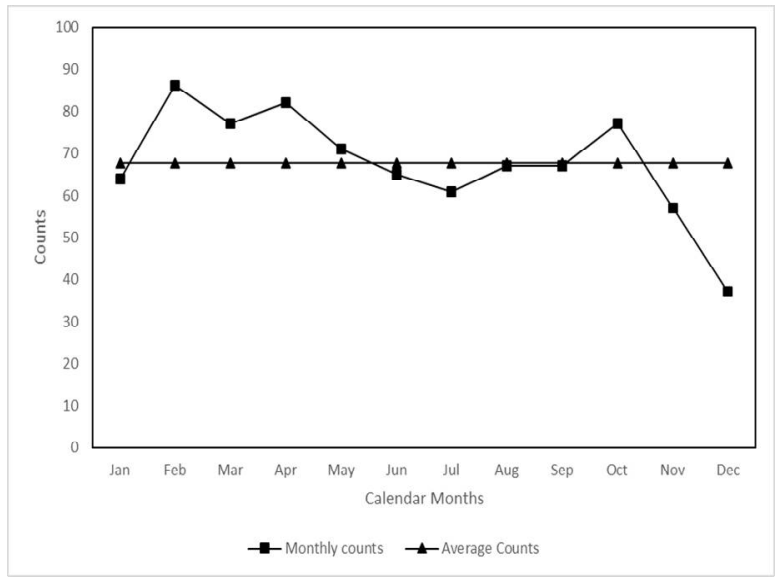

Figure 4: Combined frequencies with the mean indicated

Prescribing frequency and cost of the different trade names of antimigraine agents

The number of products prescribed and the cost of the eight active ingredients with their trade names are given in Table 1 . Clonidine and ergotamine were on average the least expensive. Although rizatriptan was the most often prescribed triptan, it was slightly more expensive than the least expensive triptan (sumatriptan). Only seven prescriptions were issued for pizotifen, which was on average the most expensive antimigraine agent. 
Table 1: Prescribing frequency and cost of the different trade names of antimigraine agents*

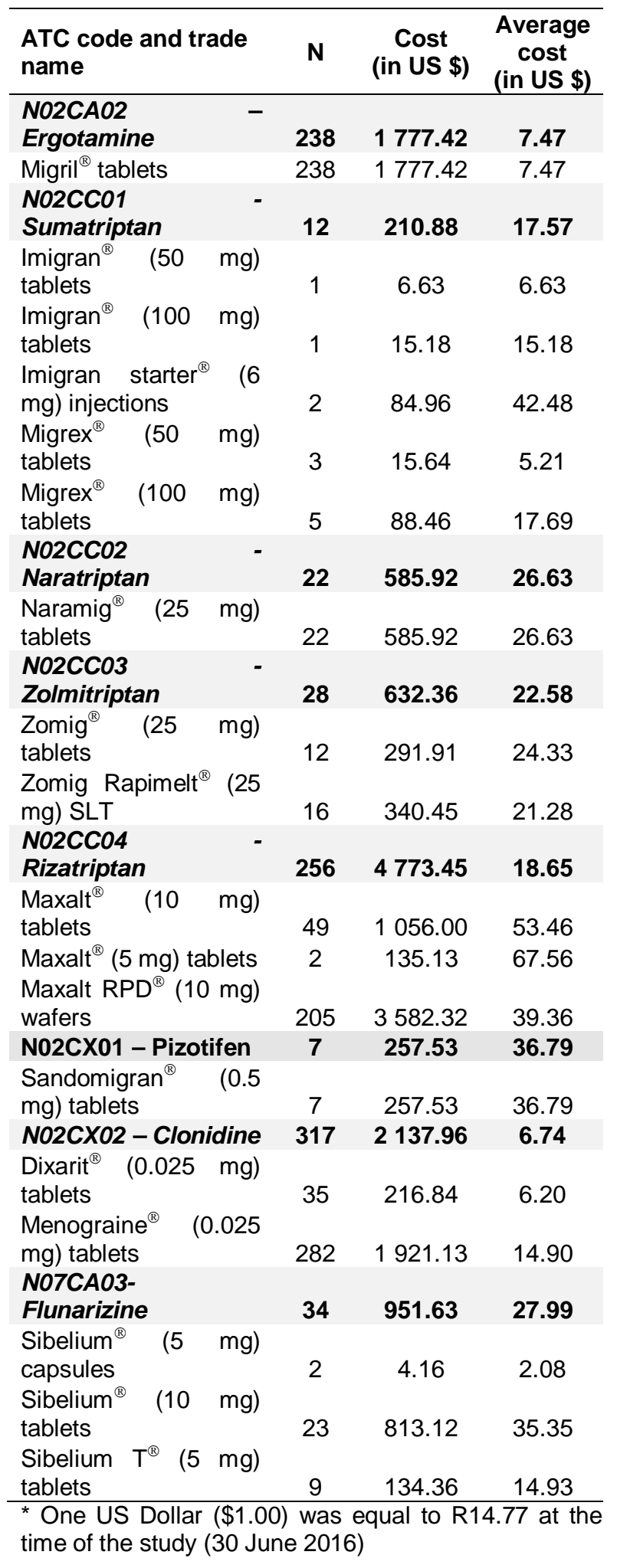

\section{DISCUSSION}

The literature reports that environmental factors, such as weather, can trigger migraine attacks. In the absence of published studies in South Africa on this topic, we decided to interrogate a medical insurance scheme administrator database to determine if seasonal patterns in the prescribing of antimigraine agents can be identified.

The demographic information of patients was in agreement with the findings of previous South African studies on antimigraine prescribing patterns $[28,29]$, in terms of the age and gender distribution of patients. The number of products dispensed decreased towards the end of the year. The low prescription frequency in December was expected and is a typical observation in many South African medical aid database studies. Possible reasons are due to the medical insurance scheme benefits of patients being depleted at the end of the year, or patients do not fill their prescriptions since it is the summer holiday period (December is a holiday month in South Africa), or in the case of migraine, it can also be because the holiday month is generally regarded as a less stressful period. The average number of products that was prescribed per patient (1.81 products over the 12 months) was expected, since these products are usually not used on a continuous or chronic basis.

Five triptans are available in the South African market [24]. Eletriptan was not prescribed in this study. The triptans are relatively expensive and are therefore not always the first-line therapy for migraine. In addition, in this study, only sumatriptan had a generic equivalent that was prescribed. Despite the fact that sumatriptan was the least expensive triptan, rizatriptan was more often prescribed. In a South African study conducted on 2008 data, rizatriptan was also the most often prescribed triptan [28]. In a randomised, double-blind, parallel-group, placebo-controlled, outpatient trial of 449 migraine patients, it was reported that the antimigraine effect of 10 and $20 \mathrm{mg}$ rizatriptan was superior to placebo, and comparable with that of $100 \mathrm{mg}$ sumatriptan succinate [30]. The efficacy of $40 \mathrm{mg}$ rizatriptan was also reported to be superior to that of both placebo and $100 \mathrm{mg}$ sumatriptan succinate, although it was associated with a high frequency of adverse events [30]. It is furthermore generally reported that rizatriptan acts faster than sumatriptan to reduce migraine symptoms.

From the analysis of seasonal variations in antimigraine agent prescribing, it seemed as if there were prescribing differences between the months. Rizatriptan and clonidine showed significantly different seasonal prescribing patterns. Clonidine is not exclusively used for migraine. Clonidine is also used for hypertension, and it is indicated for Attention-Deficit/Hyper- 
activity Disorder (ADHD) and hot flushes. Clonidine was more often prescribed to female patients, which is consistent with its use in migraine as well as for hot flushes in females. The other active ingredient which showed a clear seasonal pattern is rizatriptan, with peaks during seasonal change (autumn and spring) in South Africa.

A study conducted on meteorological parameters and patients presenting with migraine headache in an emergency department by Yilmaz et al [27], reported a statistically significant correlation between the number of daily patients and daily maximum temperature $(p=0.005)$, mean temperature $(p=0.013)$, minimum temperature $(p=0.041)$, and daily temperature change $(p=$ 0.003 ). In addition, a negative correlation was found between the number of patients presenting at the emergency department daily and the concurrent relative humidity (in percentage; $p=$ 0.031). The authors concluded that the number of patients admitted to the emergency department with migraine headache has increased with high temperature and low humidity [27]. South Africa is a country with climate extremes, from arid or desert areas, to areas with snow-covered mountains in winter. No studies could be found that have investigated the prevalence of migraine in the different areas of the country, or that related migraine prevalence to weather parameters (for example, temperature changes, high winds, barometric pressure or extremely dry conditions). The results of such studies could add important information for better understanding of migraine prevalence and factors that trigger attacks.

\section{Limitations of the study}

The study had several limitations. The database did not include detailed diagnoses codes (ICD-10 codes) and the MIMS drug classification system was used as a proxy for diagnoses by identifying when the different antimigraine agents were prescribed. Secondly, it was not known on exactly which dates the antimigraine agents were actually used, however, the number of prescriptions dispensed in each month gave an indication of when the agents were dispensed during the year which is presumably closely related to the times when they were used. Thirdly, there was no confirmation that the medicine was actually consumed since retrospective dispensing records were used.

\section{CONCLUSION}

Despite these limitations, the study reported on an area that warrants research in South Africa.
Several international studies have reported weather as a migraine trigger factor and have indicated that migraine attacks can be linked to specific seasons. Although no definitive conclusion could be made from this South African study due to the small sample size, it seems as if antimigraine prescribing peaked when the seasons changed (autumn and spring), possibly confirming that weather is a trigger factor. This is an interesting finding and warrants further research using larger databases, as well as patient studies where more variables related to weather as a migraine trigger factor can also be investigated.

\section{DECLARATIONS}

\section{Acknowledgement}

Providence Healthcare Risk Managers, South Africa provided the data for the study.

\section{Conflict of interest}

The authors declare that no conflict of interest is associated with this work.

\section{Contribution of authors}

We declare that this work was done by the authors named in this article and all liabilities pertaining to claims relating to the content of this article will be borne by the authors. IT designed the study, collected and analysed the data, and wrote the manuscript. BL conceived the study, read and approved the manuscript for publication. TK did the statistical analysis, and read and approved the manuscript for publication.

\section{REFERENCES}

1. Migraine. The International Classification of Headache Disorders, 3rd ed (Beta version), 2016. [cited $2017 \mathrm{Jul}$ 22]. Available from: https://www.ichd-3.org/1-migraine/

2. Martelletti $P$, Birbeck $G L$, Katsarava $Z$, Jensen $R H$, Stovner LJ, Steiner TJ. The Global Burden of Disease survey 2010, Lifting the burden and thinking outside-thebox on headache disorders. J Headache Pain 2013; 14 : 13. [cited 2017 Jul 22]. Available from: http://www.thejournalofheadacheandpain.com/content/1 4/1/13

3. Iliopoulos $P$, Damigos $D$, Kerezoudi E, Limpitaki G, Xifaras $M$, Skiada $D$, Tsagkovits $A$, Skapinakis $P$. Trigger factors in primary headaches subtypes: $A$ crosssectional study from a tertiary centre in Greece. BMC Res Notes 2015; 8:393. doi:10.1186/s13104-015-13901397. 
4. Fukui $P T$, Gonçalves TRT, Strabelli CG, Lucchino NMF, Matos FC, dos Santos JPM, Zukerman E, ZukermanGuendler V, Mercante JP, Masruha MR, et al. Trigger factors in migraine patients. Arq Neuropsiquiatr 2008; 66(3-A): 494-499.

5. Okuma $H$, Okuma $Y$, Kitagawa $Y$. Examination of fluctuations in atmospheric pressure related to migraine. SpringerPlus 2015; 4: 790. doi:10.1186/s40064-0151592-4.

6. Hoffmann J, Recober A. Migraine and triggers: Post hoc ergo propter hoc? Curr Pain Headache Rep 2013, 17(10). doi:10.1007/s11916-013-0370-7.

7. Lilleng $H$, Bekkelund $S$. Seasonal variation of migraine in an arctic population. Headache 2009; 49: 721-725. doi: 10.1111/j.1526-4610.2008.01239.x.

8. Barrie MA, Fox WR, Weatherall M, Wilkinson MIP. Analysis of symptoms of patients with headaches and their response to treatment with ergot derivatives. QJM Med 1968; 37: 319-336.

9. Wilkinson M, Woodrow J. Migraine and Weather. Headache 1979; 19: 375-378.

10. Osterman PO, Lövstrand KG, Lundberg PO, Lundquist $S$, Muhr C. Weekly headache periodicity and the effect of weather changes on headache. Int J Biometeorol 1981; 25: 39-45.

11. Cull RE. Barometric pressure and other factors in migraine. Headache 1981; 21: 102-103.

12. Kelman $L$. The triggers or precipitants of the acute migraine attack. Cephalalgia 2007; 27: 394-402.

13. Robbins L. Precipitating factors in migraine - $A$ retrospective review of 494 patients. Headache 1994; 34: 214-216.

14. Rasmussen BK. Migraine and tension-type headache in a general population: Precipitating factors, female hormones, sleep pattern and relation to lifestyle. Pain 1993; 53: 65-72.

15. Chillemi S. Weather-Related Migraines. Neurology Now 2013; 9(3): 12-15.

16. Weather as a Headache and Migraine Trigger. WebMD. 2017. [cited 2017 Jul 22]. Available from: http://www.webmd.com/migrainesheadaches/headache-and-migraine-trigger-weather\#1

17. Bolay $H$, Rapoport A. Does low atmospheric pressure independently trigger migraine? Headache 2011; 51(9): $1426-1430$
18. Hoffmann J, Lo H, Neeb L, Martus $P$, Reuter U. Weather sensitivity in migraineurs. J Neurol 2011; 258(4): 596602.

19. Robbins L. Precipitating Factors in Migraine: $A$ Retrospective Review of 494 Patients. Headache 1994; 34(4): 214-216.

20. Burke W, Robinson J. The Occurrence of Migraine Auras and Possible Triggers. Scientific Res 2014; 6, 26882696.

21. Alstadhaug KB, Salvesen R, Bekkelund SI. Seasonal variation in migraine. Cephalalgia 2005; 25: 811-816.

22. Monthly Index of Medical Specialties (MIMS). Saxonwold: MIMS 2016; 56(4).

23. ATC/DDD Index 2017. World Health Organization Collaborating Centre for Drug Statistics Methodology, Oslo (Norway); 2016; [cited 2017 Jun 12]. Available from: https://www.whocc.no/atc_ddd_index/

24. South African Medicines Formulary (SAMF), 12th ed. Rossiter D (ed). Cape Town: Health and Medical Publishing Group of the South African Medical Association; 2016.

25. ICD-10 Version: 2016. ICD-10 - World Health Organization, 2016. [cited 2016 Aug 12]. Available from: http://apps.who.int/classifications/icd10/browse/2016/en

26. The Belmont Report: Ethical Principles and Guidelines for the Protection of Human Subjects of Research. Bethesda: The Commission; 1978.

27. Yilmaz M, Gurger M, Atescelik M, Yildiz M, Gurbuz S. Meteorologic parameters and migraine headache: $E D$ study. Am J Emerg Med 2-15; 33: 409-413.

28. Truter I. Prescribing for migraine with the focus on selective 5HT1-receptor agonists: a pharmacy database analysis. Int J Clin Pharmacol Ther 2010; 48(5): 319326.

29. Truter I, Kotze TJ van W. Prescribing of drugs for the treatment of migraine with specific emphasis on sumatriptan. Health SA Gesondheid 2004; 9(4): 53-63.

30. Visser WH, Terwindt GM, Reines SA, Jiang K, Lines CR, Ferrari $M D$. Rizatriptan vs sumatriptan in the acute treatment of migraine. A placebo-controlled, doseranging study. Dutch/US Rizatriptan Study Group. Arch Neurol 1996; 53(11): 1132-1137. 